In the United States, lorazepam, with its longer half-life compared to diazepam, is considered most appropriate as initial treatment for generalized tonic-clonic status epilepticus. (Wheless JW et al. Eds. Treatment of pediatric epilepsy: Expert opinion 2005. J Child Neurol Dec 2005;20(Suppl 1):S46-S49). If the seizure continues despite the maximum dose of benzodiazepine, this is followed with IV fosphenytoin as the most appropriate second drug selection.

\title{
TOPIRAMATE AND VALPROATE COMPARED IN TREATMENT OF JUVENILE MYOCLONIC EPILEPSY
}

A pilot, randomized, controlled trial comparing topiramate $(n=19)$ and valproate $(\mathrm{n}=9)$ in adolescents/adults with juvenile myoclonic epilepsy (JME) was conducted in the Childrens Hospitals of Denver, $\mathrm{CO}$, and Cincinnati, $\mathrm{OH}$. Of patients completing a 26 week trial of these agents titrated to optimal effect, 8 of $12(67 \%)$ in the topiramate group and 4 of $7(57 \%)$ in the valproate group were seizure-free during the 12 -week maintenance period. Median daily doses were $250 \mathrm{mg}$ topiramate and $750 \mathrm{mg}$ valproate. Adverse events resulted in discontinuance of treatment in $2(11 \%)$ of topiramate-treated and one $(11 \%)$ valproatetreated patients. Valproate had a higher incidence of systemic toxicity than topiramate, including nausea $(33 \%)$, weight gain $(22 \%)$, increased appetite $(22 \%)$, alopecia $(33 \%)$ and rash $(22 \%)$. A double-blind trial of topiramate in JME is recommended. (Levisohn PM, Holland KD. Topiramate or valproate in patients with juvenile myoclonic epilepsy: A randomized open-label comparison. Epilepsy \& Behavior 2007;10:547-552).

COMMENT. Topiramate may be an effective alternative treatment to valproate for juvenile myoclonic epilepsy (JME). An expert opinion panel rated valproate and lamotrigine as most appropriate treatment for JME in males, and lamotrigine followed by topiramate in females. (Wheless JW et al. J Child Neurol 2005;20(Suppl 1):S42-S43). Zonisamide and levetiracetam are rated sometimes appropriate. Valproate is not recommended in adolescent and young adult females with JME because of risk of teratogenicity and potential harmful effects on the infant's neuropsychological development (Eriksson $\mathrm{K}$ et al. Epilepsy Res $2005 ; 65: 189-200)$.

Levetiracetam in severe myoclonic epilepsy of infancy (Dravet syndrome). Levetiracetam add-on therapy was administered in doses of 10 up to $50-60 \mathrm{mg} / \mathrm{kg} /$ day in 28 children (mean age $9.4+/-5.6$ years) with SMEI (16 with $S C N 1 A$ mutations). Mean dose was 2,016 mg/day. Tonic-clonic, myoclonic, and focal seizures responded in 60-64\% cases, and absence seizures in $44 \%$. Myoclonic seizures were reduced from 21 to 3 per week ( $\mathrm{p}=.002$ ), and tonic-clonic from 3 to 1 week $(\mathrm{p}=.0001)$. Dravet syndrome is a drug-resistant epilepsy with onset in the first year of life. It is characterized by prolonged and repeated febrile and afebrile generalized or focal convulsive seizures. Myoclonic and partial seizures develop between 1 and 4 years of age. Psychomotor development, initially normal, is delayed in the $2^{\text {nd }}$ year. Seizures are usually refractory to treatment. 